\title{
COMPREHENSIB ILITY OF ROAD TRAFFIC SIGNS AMONG URBAN DRIVERS (CASE STUDY; SUNYANI MUNICIPALITY, GHANA)
}

\author{
Kwadwo Appiah Boateng ${ }^{1}$, Harold Atobra-Acheampong ${ }^{2}$, Nana Poku Agyeman ${ }^{3}$, \\ Emmanuel Adu Gyamfi ${ }^{4}$ \\ ${ }^{1}$ Lecturer, Department of Civil Engineering, Sunyani Polytechnic, Sunyani, Ghana \\ ${ }^{2}$ Road Area Manager, Ghana Highway Authority, Kumasi, Ghana \\ ${ }^{3}$ Metro Roads Engineer, Department of Urban Roads, Kumasi, Ghana \\ ${ }^{4}$ Platoon leader, 1st Infantry, 4th Battalion Regiment, USA \\ kappiccuss@yahoo.com,hatobra@gmail.com,nanpokus@yahoo.com,emnls@yahoo.com.
}

\begin{abstract}
Road traffic signs are the oldest and most commonly used devices for traffic control. The ultimate goal of road traffic signs is to control and regulate both human and vehicular traffic in a conducive user friendly environment; thereby maximizing road safety. This study investigated drivers' comprehensibility of road signs and safety in the Sunyani Municipality, Ghana with respect to their personal characteristics such as age, educational background, mode of training and training in road safety. A total of ten (10) symbolic regulatory/prohibitory signs, ten (10) warning signs and eight (8) informatory signs were investigated. Two hundred (200) questionnaires were prepared and distributed to drivers who constituted 40 private drivers, 60 mini-bus drivers, 20 bus drivers (VIP, Metro Mass Etc.) and 80 taxi drivers. The study generally showed that, drivers in the municipality have a satisfactory understanding of traffic signs since an average correct score of $82.53 \%$ was recorded. The study further establishes that the educational background, age and number of years driven do have significant influences on driver comprehensibility of road traffic signs.
\end{abstract}

Keywords: Road Traffic Signs, Traffic Safety, Comprehensibility, Driver Characteristics and Ghana

\section{INTRODUCTION}

Modern developmental trends in technology and economy has influenced a rise in the number of vehicles on roads. This has had a resultant effect of increased traffic on roads. Road users spend more time on roads hence facing higher risks of traffic accidents [1]

A study conducted by [2] revealed that more than one million two hundred and fifty people lose their lives through traffic accidents yearly. Road traffic signs are classified among the world's oldest devices for controlling traffic. These signs warn, guide and regulate road users such as pedestrians and motorists by conveying messages in symbols and words erected visibly on the side or above roads. [3]

Traffic signs are purposely developed to provide the required necessary information to support safe drive in a short time. However, the success of traffic signs in achieving road safety depends on its comprehensibility by drivers. It is therefore imperative that traffic signs be simple, command attention, convey clear precise meaning as well as well as provide an accommodating time for drivers to respond appropriately [4]. According to [5] traffic signs employ the use of colour, words and symbols to convey the required information for drivers to appreciate and respond accordingly. In this light, it can be reiterated that traffic signs cannot serve the purpose for their erection if drivers do not comprehend the information encoded in the signs.

The Organization of International Standardization (ISO 3864) advice that traffic signs should meet $85 \%$ comprehensibility [6] whiles the American National Standard Institute (ANSI Z535.3) recommends a $67 \%$ comprehensibility [7]. The Driver Vehicle Licensing Authority (DVLA) in Ghana pegs it that $70 \%$ comprehensibility [8].

In the recent past, traffic signs and road accident occurrences have generated a lot of research interests in this regard. There has always been a general perception that, drivers in the municipality do not have satisfactory levels of traffic sign comprehensibility and this is thought to be a cause of concern of road accidents.

This research henceforth seeks to analyze drivers' personal characteristics in understanding road traffic signs in Sunyani Municipality.

The Sunyani Municipality can be found in between the Latitudes $7055^{\prime} \mathrm{N}$ and $7035^{\prime} \mathrm{N}$ and the Longitudes $20 \mathrm{~W}$ and $2030^{\prime} \mathrm{W}$. The municipality is bounded to the north by Wenchi, to the west by Berekum and to the East by Tano South Districts. The Municipality spans a land area of 24885 kilo metres square. 

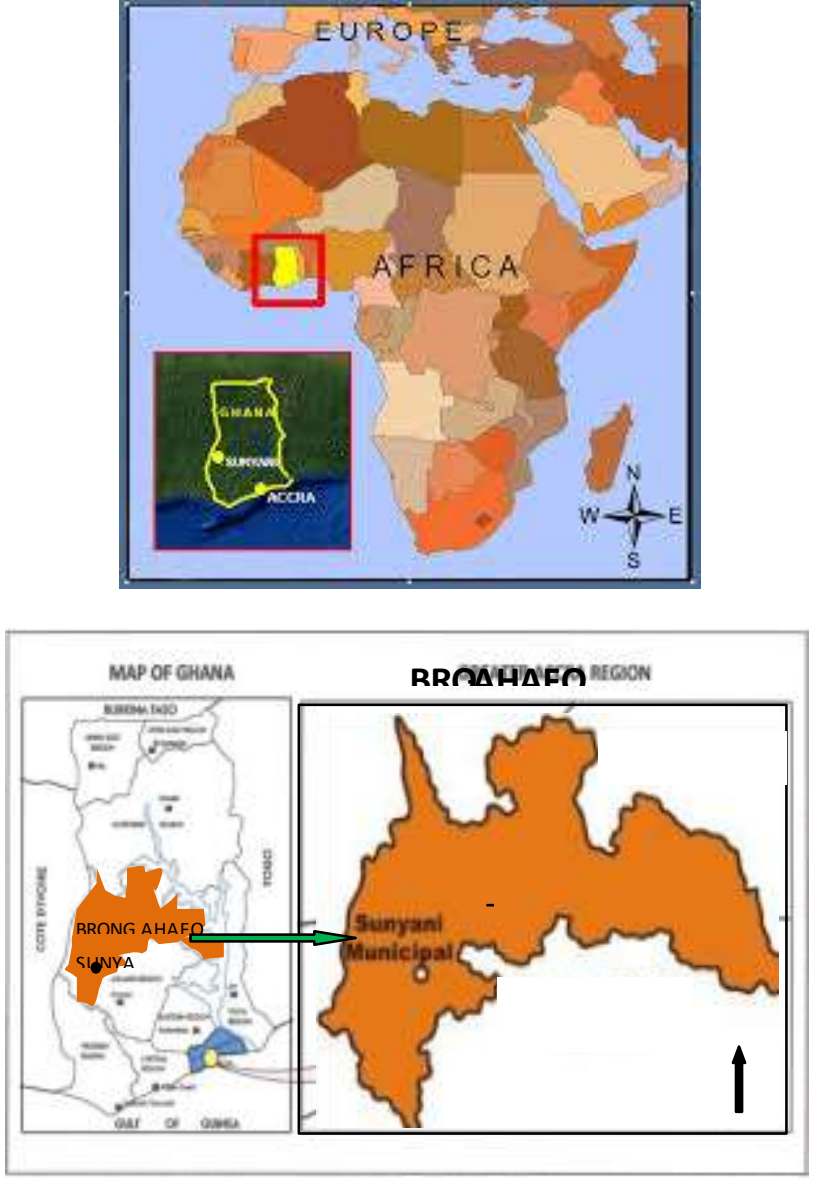

Fig. 1: Study Area in Context

\section{LITERATURE REVIEW}

Road sign is one of the important features on a highway, it shows direction and gives location of where you are and what is ahead of you. Road signs have clear and concise meanings.

Road traffic signs are installed either sideways or high above roads. Their purpose is to provide the required information for road users. In the design of road traffic systems, the function of the traffic signs is to provide road users, particularly drivers with information about system conditions (such as their location in relation to other areas) in order to allow them to anticipate events and where necessary to encourage them to adjust their behavior appropriately. [9]

The United Kingdom (UK) first introduced road signs as simple milestones and directional route arm signs. Subsequently as traffic volumes increases drastically, many countries adopted pictorial signs to enhance user comprehensibility by overcoming and eliminating language barriers. [10]

Primarily, road signs serve to provide very useful information to road users. These information help drivers to respond with the appropriate behavior to prevent accidents.

In this regard, the main motif of regulating and moderating speed and other conditions by strict compliance will lose its effectiveness if regulatory operators fail in their capacity to enforce these signs. Signs are expected to be efficient and clear since drivers depend on the information provided as a form of guidance. On the other hand, highway officials rely on signs to efficiently work in enforcing traffic regulations for traffic control as a means of ensuring road safety.

Signs can be grouped under three (3) broad umbrellas namely Regulatory, Warning and Informatory Signs.

2.1.1 Regulatory signs: These signs serve notices of restrictions, requirements and prohibition. Usually regulatory signs are circular in shape. They include the STOP sign, GIVE WA Y etc., basically signs that assign the right of passage to merg ing roads or interceptions. [11].

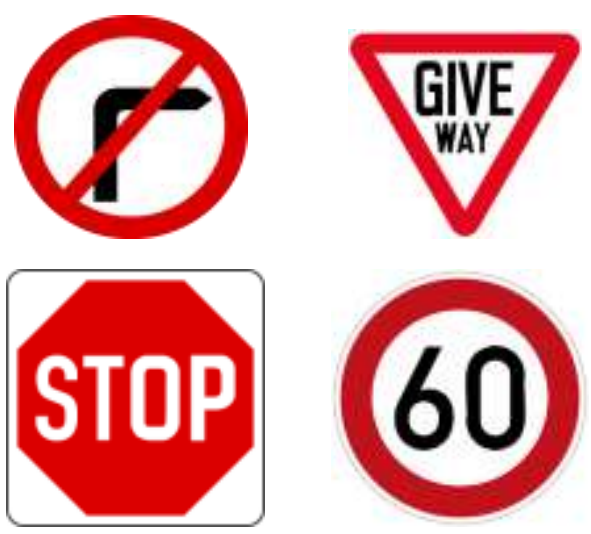

Figure 2.1. Examp les of regulatory signs.

2.1.2 Warning sign: These signs generally provide information to drivers about impending conditions on the road. Thus, these signs seek to provide forehand advice about approaching conditions for drivers to prepare themselves vigilantly to respond adequately to the condition. Below are some examples.
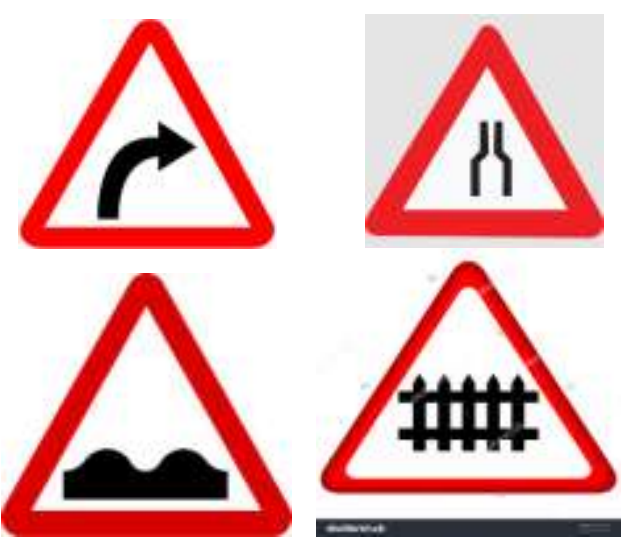

Figure 2.2. Examples of warning signs.

2.1.3 Informatory signs: As the name suggests Informatory signs give drivers information about places and facilities and routes of particular interest or value. Usually these signs are rectangular but directional signs normally have one end pointed [9]. 


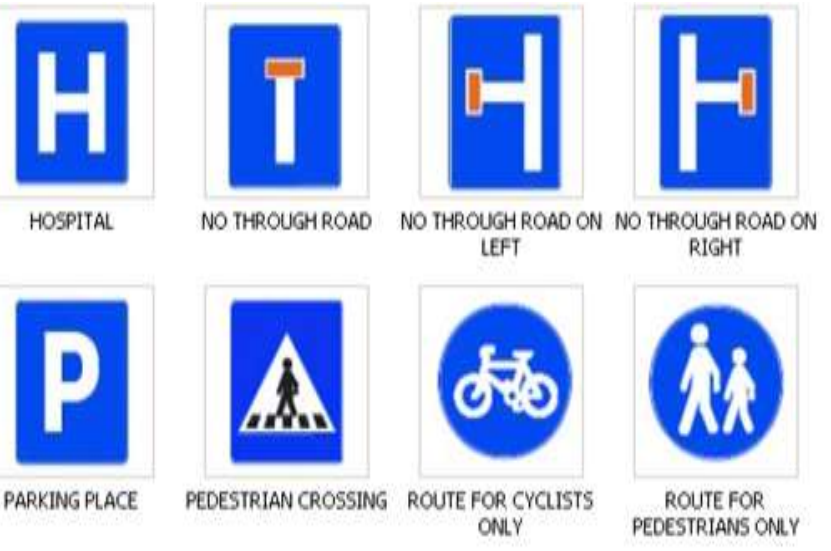

Figure 2.3. Examp les of informatory signs.

\section{METHODOLOGY}

The research used questionnaires to harness data for the purpose of the study. These questionnaires were administered randomly to intra city (urban) drivers within the Sunyani Municipality. In all two hundred (200) questionnaires were administered at various Taxi Ranks, Lorry Parks and also to various professionals who drive in the municipality. Since the drivers completed the questionnaires on the spot all questionnaires administered were retrieved.

The questionnaire was categorized into three sections. The first section was developed to harness information on the personal and socio-economic characteristics of drivers such as sex, age, educational background etc. The second section also sought to obtain information about driver characteristics such as driving experience, mode of training etc. The last section had twenty-eight (28) multiple choice questions which included ten (10) regulatory signs, ten (10) warning signs and ten (8) informatory signs.

\subsection{Research questions}

This research study seeks to find answers to the following questions;

- What is the level of understanding of road signs by drivers in Sunyani?

- What is the mode of training of drivers in the Sunyani Municipality?

- Does a driver's level of education have an influence on his comprehensibility of road signs?

- Does the age and number of years driven have an influence on road sign comprehensibility?

\section{RESULTS \& DISCUSSION}

\subsection{Characte ristics of Drive rs}

As indicated in the introductory section, the characteristics of drivers, which are indicative of their capacity are age, educational background, years of driving, training in road safety as well as the mode of training. The survey revealed that all the drivers had license. These are examined seriatim.
Table 1. Educational Categorization of Drivers

\begin{tabular}{|c|c|c|}
\hline EDUCATION & DRIVERS & PERCENTAGE \\
\hline Primary & 12 & 6 \\
\hline Middle/JHS & 100 & 50 \\
\hline Secondary & 50 & 25 \\
\hline Tertiary & 24 & 12 \\
\hline Never Schooled & 14 & 7 \\
\hline
\end{tabular}

Table 2. Age Categorization of Drivers

\begin{tabular}{|c|c|c|}
\hline AGE (YEARS) & DRIVERS & PERCENTAGE \\
\hline $18-24$ & 26 & 13 \\
\hline $25-34$ & 91 & 46 \\
\hline $35-44$ & 54 & 27 \\
\hline $45-$ above & 29 & 14 \\
\hline
\end{tabular}

Table 3. Type of Vehicle Respondents Drive

\begin{tabular}{|c|c|c|}
\hline VEHICLE TYPE & DRIVERS & PERCENTAGE \% \\
\hline Private & 40 & 20 \\
\hline Mini Bus & 60 & 30 \\
\hline Bus & $\mathbf{2 0}$ & $\mathbf{1 0}$ \\
\hline Taxi & $\mathbf{8 0}$ & $\mathbf{4 0}$ \\
\hline
\end{tabular}

Table 4. Nu mber of Years Driven

\begin{tabular}{|c|c|c|}
\hline YEARS OF DRIVING & DRIVERS & PERCENTAGE \% \\
\hline $\mathbf{1 - 5}$ & $\mathbf{7 2}$ & $\mathbf{3 6}$ \\
\hline $\mathbf{6}-\mathbf{1 0}$ & $\mathbf{6 6}$ & $\mathbf{3 3}$ \\
\hline Above 10 & 62 & 31 \\
\hline
\end{tabular}

Table 5. Training on Road Safety

\begin{tabular}{|c|c|c|}
\hline $\begin{array}{r}\text { TRAINING ON } \\
\text { ROAD SAFETY }\end{array}$ & DRIVERS & PERCENTAGE \% \\
\hline Yes & 137 & 68 \\
\hline No & 63 & 32 \\
\hline
\end{tabular}

Table 6. Mode of Training of Drivers

\begin{tabular}{|c|c|c|}
\hline $\begin{array}{c}\text { MODE OF } \\
\text { TRAINING }\end{array}$ & DRIVERS & PERCENTAGE \% \\
\hline Apprenticeship & 141 & 71 \\
\hline Driving School & 45 & 22 \\
\hline Others & 14 & 7 \\
\hline
\end{tabular}

The study identified two main modes of training of drivers before licensing - professional driver training (Formal training) and informal driver training. Informal training which includes apprenticeship (conductors graduating to be drivers) and learning through a friend or relative, constituted the majority of about $78 \%$ of the various modes of driver training. Training of drivers by accredited driving schools, on the other hand constituted about $22 \%$. It is believed that, due to high cost in acquiring training from licensed driving schools, most $(78 \%)$ of the drivers obtained driving lessons fro m outside the traditional driving schools. 


\subsection{Drivers Unde rstand of Traffic Signs}

\subsubsection{Regulatory road sign}

A total of ten (10) Regulatory signs were evaluated in this study. The results of drivers' understanding of the regulatory signs are presented in table below. The average percentage of correct answers was $90.9 \%$ which indicate that the understanding was very satisfactory as it is above the DVLA standard of $70 \%$. This high percentage comprehensibility can be attributed to the self-explanatory graphics in the signs.

Table 7. Regulatory Sign Responses

\begin{tabular}{|c|c|c|}
\hline ROAD SIGN & MEANING & $\begin{array}{l}\text { PERCENTAGE } \\
\text { CORRECT } \\
\text { ANSWERS }\end{array}$ \\
\hline & $\begin{array}{l}\text { Right turn } \\
\text { prohibited }\end{array}$ & $80 \%$ \\
\hline & Stop & $95 \%$ \\
\hline & $\begin{array}{l}\text { Give way to } \\
\text { vehicle on } \\
\text { major road }\end{array}$ & $91 \%$ \\
\hline & Speed Limit & $98 \%$ \\
\hline & $\begin{array}{c}\text { U-Turn } \\
\text { Prohibited }\end{array}$ & $90 \%$ \\
\hline & $\begin{array}{c}\text { Parking } \\
\text { Prohibited }\end{array}$ & $98 \%$ \\
\hline & $\begin{array}{c}\text { Bicycle } \\
\text { Prohibited }\end{array}$ & $96 \%$ \\
\hline
\end{tabular}

\begin{tabular}{|l|l|l|}
\hline & No Pedestrian \\
Crossing & $\mathbf{8 2 \%}$ \\
\hline DO NOT & No Left turn & $\mathbf{8 9 \%}$ \\
\hline ENTER & No Entering & $\mathbf{9 1 \%}$ \\
\hline TOTAL & & \\
\hline
\end{tabular}

\subsubsection{Warning/Cautionary road signs}

A total of ten (10) Warning signs were evaluated in this study. The results of drivers' understanding of the Warning signs are presented in the table below. The average percentage of correct answers was $78.7 \%$ which indicate that the understanding was satisfactory per DVLA acceptable standard of $70 \%$, however school ahead sign and road closed sign recorded a significant low of $54 \%$ and $45 \%$ respectively.

Table 8. Warn ing Sign Responses

\begin{tabular}{|c|c|c|}
\hline ROAD SIGN & MEANING & $\begin{array}{c}\text { PERCENTAGE } \\
(\%)\end{array}$ \\
\hline & $\begin{array}{c}\text { Pedestrian } \\
\text { Crossing }\end{array}$ & $70 \%$ \\
\hline & $\begin{array}{c}\text { Narrow Road } \\
\text { Ahead }\end{array}$ & $84 \%$ \\
\hline & $\begin{array}{l}\text { Right Hand } \\
\text { Curve }\end{array}$ & $83 \%$ \\
\hline & School Ahead & $54 \%$ \\
\hline
\end{tabular}




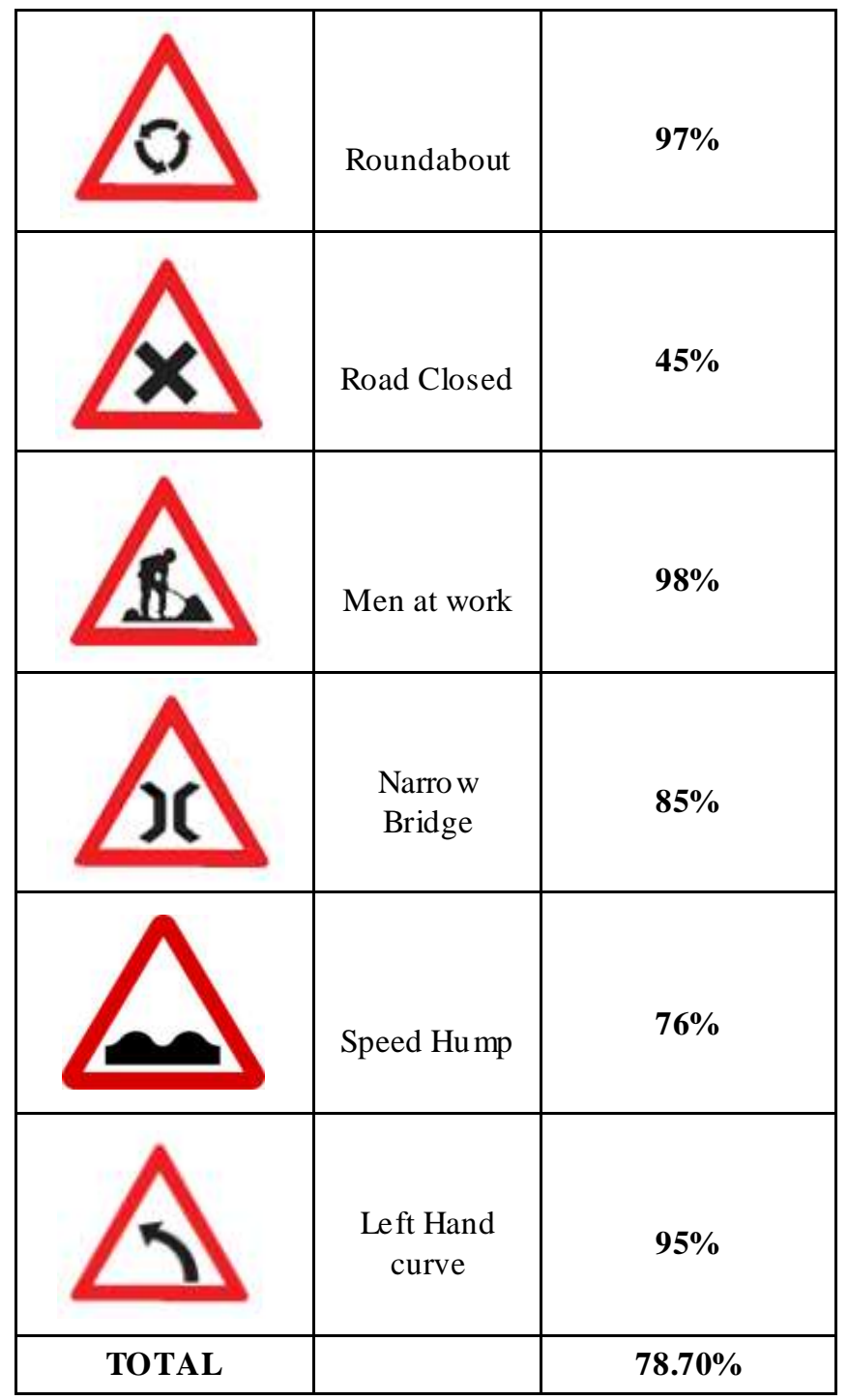

\subsubsection{Informatory road signs}

The results of drivers' understanding of the Informatory signs are presented in table below. The average percentage of correct answers was $62.3 \%$ which indicate that the understanding was unsatisfactory.

Table 9. Informatory Sign Responses

\begin{tabular}{|c|c|c|}
\hline ROAD SIGN & MEANING & $\begin{array}{c}\text { PERCENTAGE } \\
\text { OF CORRECT } \\
\text { RESPONS ES } \\
(\%)\end{array}$ \\
\hline & $\begin{array}{c}\text { Hospital } \\
\text { Ahead }\end{array}$ & $\mathbf{9 2 \%}$ \\
\hline & $\begin{array}{c}\text { No through } \\
\text { road Ahead }\end{array}$ & $\mathbf{5 8 \%}$ \\
\hline
\end{tabular}

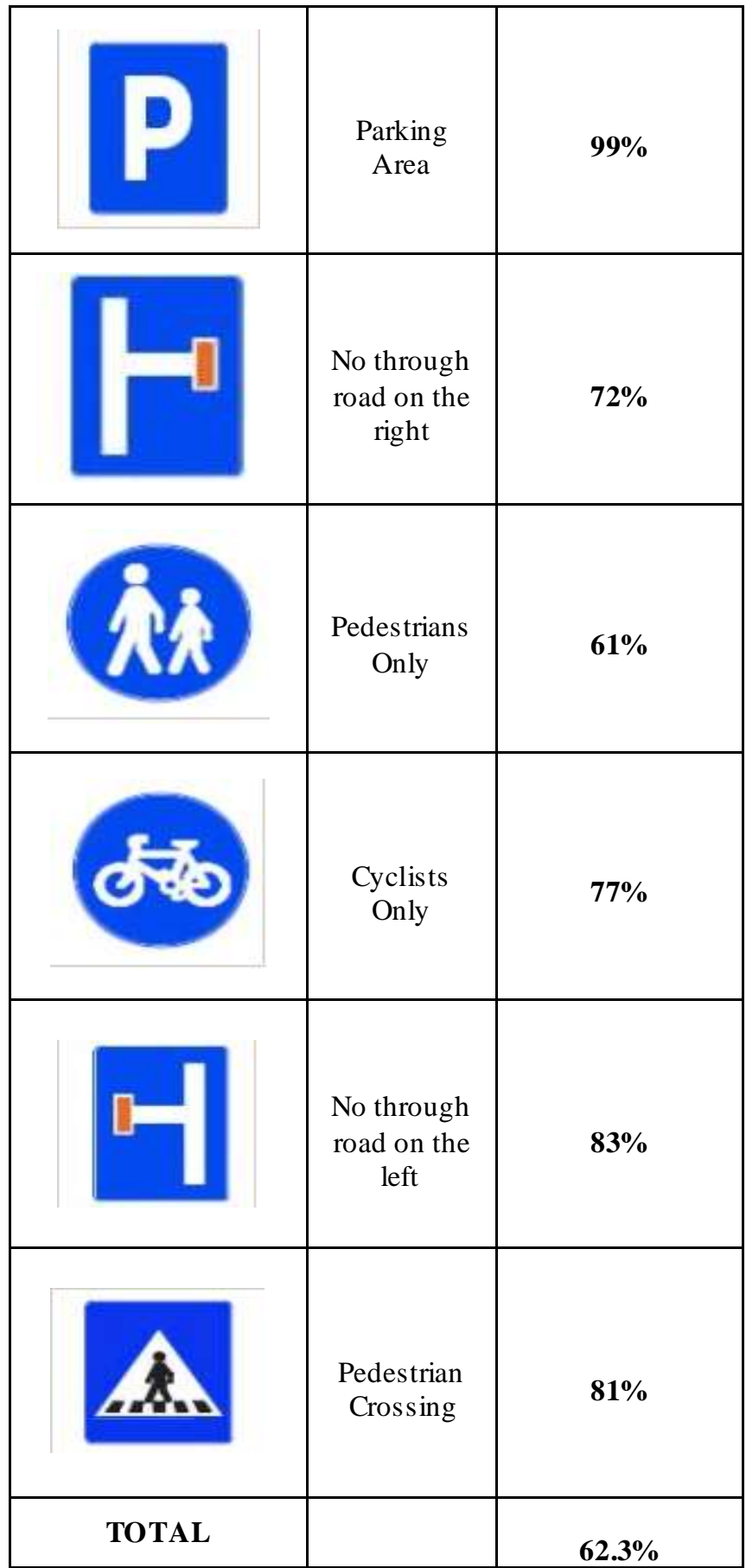

\subsection{Relationship between Age Groups and Average} Percentile of Correct Ans wers

After analyzing the average percentages of signs answered correctly based on the age groupings of respondents, it was established that Age Groups (25-34) and (35-44) scored an average of $92.9 \%$ and $89.3 \%$ respectively and Age Groups (18-24) and (45-above) scored $74.5 \%$ and $79.3 \%$ respectively. This shows that drivers with Age Groups (25$34)$ and (35-44) do have a better understanding of traffic signs more their younger and older colleagues. This is shown in Fig 2.0 below. 


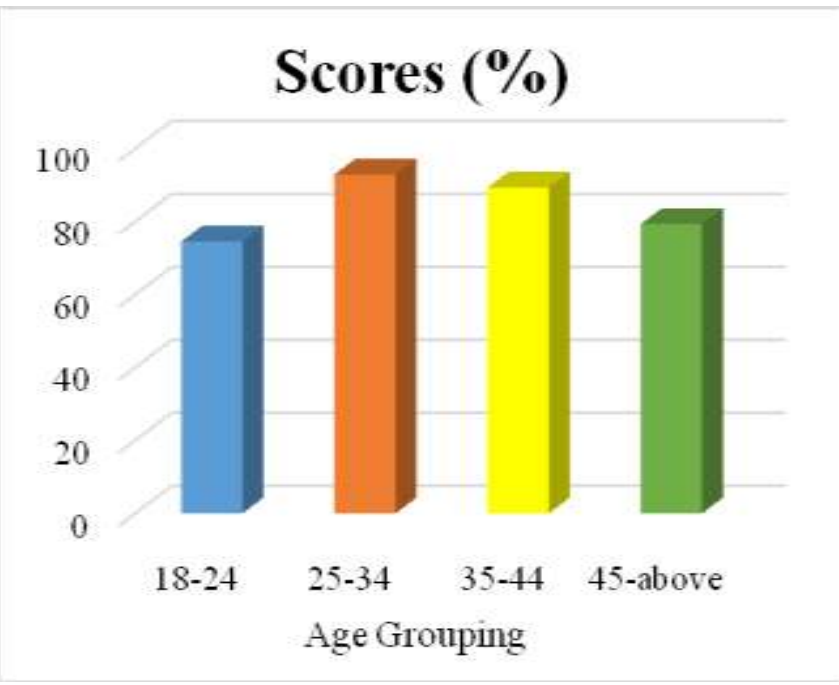

Fig 2. Plot of Age Groups against Percentage Correct Answers

\subsection{Relationship between Educational Background and Average Percentile of Correct Ans wers}

The study revealed that, drivers who had never been to school had an average score of $64.3 \%$, those with primary education had $70.2 \%$ correct, those who had middle/JHS education had $85.7 \%$, those who had secondary education had $92.9 \%$ correct, those who had tertiary education had $96.4 \%$ correct. This clearly portrays that road sign comprehensibility increases with increasing level of education. Graphically shown in Fig 3.0 below.

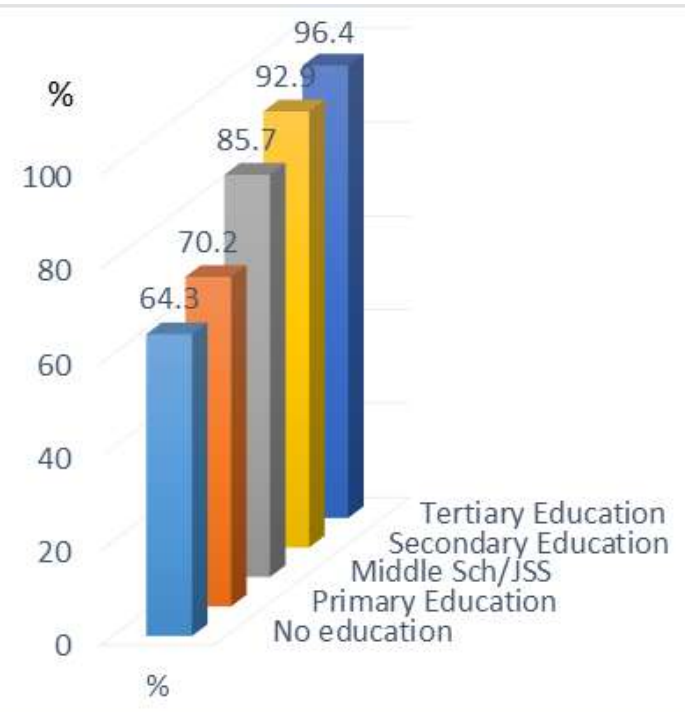

Fig 3. Plot of Educational level against Percentage Correct Answers

\subsection{Relationship between Driving Experience and}

\section{Average Percentile of Correct Ans we rs}

The study further showed that driving experience has an important role to play in the respondents driving careers, this is because respondents with (1-5) years driving experience had an average score of $71.4 \%$, those with 6-10 years driving experience had $82.1 \%$ and those with 10 years and above had $89.3 \%$. It is therefore worth mentioning that road sign comprehensibility increases as one drives for more years. This is shown in Fig 4.0 below.

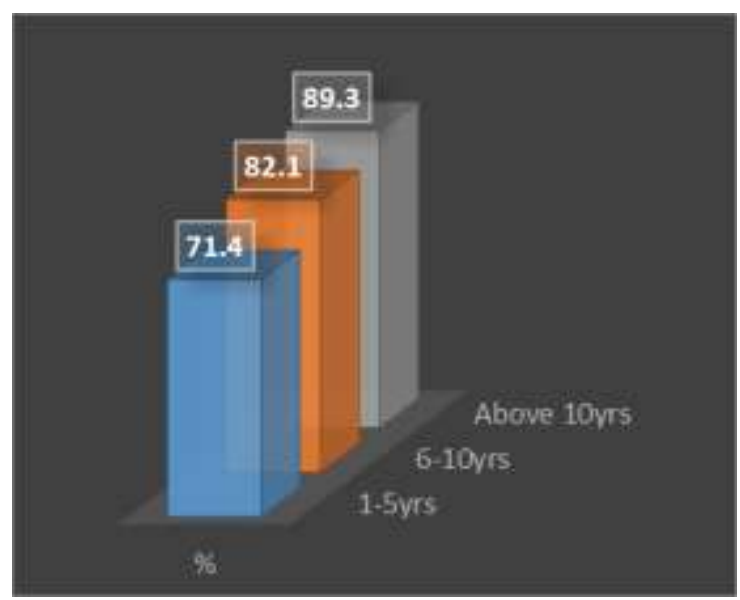

Fig 4. Plot of Driving Experience against Percentage Correct Answers.

\section{CONCLUSION}

Comprehensibility of traffic signs is very important in road safety since when signs are understood and followed it safeguards road users from rapid road accidents. The results generally showed a fair understanding of the traffic signs with the exception of the Informatory Signs which recorded a below acceptable limit of $62.3 \%$, both the regulatory and warning signs recorded a satisfactorily $90.9 \%$ and $78.7 \%$ respectively. Averagely, a score of $82.53 \%$ was recorded which is also satisfactory per ISO 3864 , ANSI Z535.3 and DVLA, Ghana standards.

The study further established that driving experience had a part to play in traffic sign comprehension as from the results drivers who had driven more understood the signs better. The results also revealed that the older drivers above 45 years and younger ones below 24 years understood the signs less.

Another point of note, can be drawn from the trend established that drivers with higher educational backgrounds performed much better than those with low educational backgrounds. This presupposes that education has a significant effect on traffic sign comprehensibility, therefore it is imperative for Licensing and Regulatory Authorities to incorporate in their operations routine training programs directed towards educating drivers on road safety.

\section{REFERENCES}

[1] Boersema, T., \& Zwaga, H. J. G. (1989). Selecting comprehensible warning symbols for swimming pool slides. In Proceedings of the Human Factors Society 33rd Annual Meeting (pp. 994-998). Santa Monica, CA: Hu man Factors and Ergonomics Society.

[2] World Health Organization. (2004): World Report on Road Traffic Injury Prevention. Geneva: WHO Library Cataloguing 
[3] Brugger, C. (1994). Public information symbols: A comparison of ISO testing procedures. In Proceedings of Public Graphics (pp. 26.1-26.10) Utrecht, Netherlands: University of Utrecht

[4] Stokes, R. W., Rys, M. J., Russell, E. R. and Kerbs, J. (1995): Motorist Understanding of Traffic Control Devices in Kansas, Final Report No. KSU-94-7, Department of Civil Engineering, Kansas State University, Manhattan, KS.

[5] Wolff, J.S. and Wogalter, M. S. (1998): Comprehension of Pictorial Symbols: Effect of Context and Test Method, Hu man Factors, (40), 173-186.

[6] International Standards Organization (ISO). (1984). International standard for safety colours and safety signs: ISO 3864. Geneva, Switzerland

[7] A merican National Standards Institute (ANSI). (1991). Accredited standard on safety colors, signs, symbols, labels, and tags, Z535.1-5. Washington, DC: National Electrical Manufacturers

[8] Driver Vehicle Licensing Authority, (2011) Annual Report

[9] Hulbert, S., Beers, J. and Flower, P. (1979): Motorist's Understanding of Traffic Control Devices, American Automobile Association (AAA), Foundation for Traffic Safety, Falls Church, VA.

[10] Al-Madani, H. (2000): Influence of Driver's Comprehension of Posted Signs on Their Safety Related Characteristics, Accident Analysis and Prevention (32): 575-581.

[11] Al-Madani, H. and Al-Janahi, A. R. (2002): Assessment of Drivers' Comprehension of Traffic Signs Based On Their Traffic, Personal and Social Characteristics, Transportation Research Part F, (5): 63-76.

[12] Al-Madani, H. and Al-Janahi, A. R. (2002): Role of Drivers' Personal Characteristics In Understanding Traffic Sign Symbols, Accident Analys is and Prevention (34): 185196.

\section{BIOGRAPHIES}

K. Appiah Boateng obtained his Bachelor's degree in Civil Engineering from KNUST and Master's degree in Engineering Management from the University of Sunderland, U.K. He currently lectures at the Sunyani Polytechnic, Ghana.

Ing. H. Atobra Acheampong obtained his Bachelor's degree in Civil Engineering from KNUST and is currently pursuing his Masters degree in Transportation Engineering at the same University. He is a member of the Ghana Institute of Engineers. He currently works as the Road Area Manager at the Ghana Highway Authority, Kumasi, Ghana

Ing. N. Poku Agyemang obtained his Bachelor's degree in in Civil Engineering from KNUST and a Commonwealth Executive Master's degree in Business Administration also at KNUST. He is a member of the Ghana Institute of Engineers. He currently works as the Metro Roads Engineer at Department of Urban Roads, Ku masi, Ghana.

Lieutenant E. Adu Gyamfi obtained his Bachelor's degree in Civil Engineering from KNUST, Masters degree in Business
Admin istration and a Doctorate degree in Management and Organizational leadership from University of Phoenix, Arizona, U.S.A. He currently a First Lieutenant in the US Army working as a platoon leader for the 1st Infantry, 4th Battalion Regiment. 